\title{
Author Index Vol. 3, 1984
}

Alpers,M.P. 3 Bharucha, N.E. 35, 149 Chandra, V. 35, 149 Clifford Rose, F. 57, 169 Dean,G. 58 Gajdusek, D.C. 3 Gunnarsson, L.-G. 195 Haberman, S. 108,207 Hemmi,I. 129 Hogenhuis, L.A.H. 169 Kinnunen, E. 74 Klitzman, R.L. 3 Kondo, K. 21,129, 182 Neugebauer, R. 40 Oppenheimer, G.M. 40 Palm, R. 195

P. Pedro

J. de 82

97 Porras

J. 74 Rosenqvist

U. 82,97 Schoenberg

B.S. 35

149 
